\title{
Montréal Statement on the Human Right to Essential Medicines
}

\author{
THOMAS POGGE
}

On September 30-October 2, 2005, a group of individuals drawn from civil society organizations, governments, international agencies, and academic institutions came together in Montréal, Québec, Canada, for an international workshop entitled "Human Rights and Access to Essential Medicines: The Way Forward." At the conclusion of the workshop, we drafted the "Montréal Statement on the Human Right to Essential Medicines." This "Statement" is reprinted at the end of this comment, which offers some background on the problem addressed at the workshop. ${ }^{1}$

During the past 15 years, the United States and some other affluent countries have worked hard and successfully to incorporate substantial and uniform protections of intellectual property rights (IPRs) into the fabric of the global trading system. This initiative included the Trade-Related Aspects of Intellectual Property Rights (TRIPs) Agreement formulated in the so-called Uruguay Round that led up to the formation of the World Trade Organization (WTO). It was continued through a series of bilateral free-trade agreements including additional ("TRIPsplus") provisions that enable patent holders to extend (or "evergreen") their monopoly beyond the 20 years en-

Many thanks to Patricia Illingworth, Mira Johri, Doris Schroeder, and Michael Selgelid for their helpful critical comments. shrined in the TRIPs Agreement ${ }^{2}$ and also discourage, impede, and delay the manufacture of generic medicines in many other ways, for example, through provisions on data exclusivity (www. accessmed-msf.org/documents / Data $\% 20$ exclusivity\%20May\%2004.pdf) and through restrictions on the effective use of compulsory licences.

IPRs can help ensure that creative productions are protected from unauthorized modification and that their authors receive royalties or licensing income from the reproduction of their work. Much more consequential than such copyrights, however, are patents, which prohibit the unauthorized reproduction of a vast range of products and productive processes. Such patent protections are more problematic, morally, than copyrights, especially when they confer property rights in biological organisms (such as seeds used in food production), in molecules used in medicines, or in pharmaceutical research tools needed in the development of new pharmaceuticals. ${ }^{3}$ Patents of these kinds are morally problematic insofar as they, directly or indirectly, impede access by the global poor to basic foodstuffs and essential medicines.

The urgency of this concern can be gauged by examining the present condition of the global poor. Subsisting on incomes around $\$ 100$ or $\$ 200$ per person per year, the poorer half of humankind is highly exposed to lifethreatening deprivations. According to 
the official statistics, there are roughly 6500 million human beings alive today. Of these, some 850 million are chronically undernourished, 1037 million lack access to safe water, and 2600 million lack access to improved sanitation. ${ }^{4}$ About 2000 million lack access to essential medicines (www.fic.nih.gov/ about/summary.html). Approximately 1000 million have no adequate shelter and 2000 million no electricity. ${ }^{5}$ Living with such severe deprivations, poor people are bound to be susceptible and vulnerable to infectious diseases and often unable to overcome them. Today, one-third of all human deaths are from poverty-related causes: 50,000 each day, or 18 million every year ${ }^{6}$ including 10.6 million children under the age of five. ${ }^{7}$ Hundreds of millions more suffer grievously from treatable medical conditions, and the lives of even more people are shattered by severe illnesses or premature deaths in their family. Health problems of such epidemic proportions weigh down the economies of poor countries and regions, thereby perpetuating their poverty, which in turn contributes to the ill health of their populations.

Severe deprivation has always been the fate of a large segment of humankind-in slaveholding societies, under feudalism, and in the colonial period. These past deprivations were associated with what we now understand to have been grievous injustices. We must suspect that existing massive deprivations are also associated with similarly grievous social injustices today, when humankind has become so affluent in aggregate that such deprivations are clearly entirely avoidable: With $15.8 \%$ of world population, the high-income OECD countries control $80.5 \%$ of the global product, whereas the aggregate income of the poorer half of humankind is well below $2 \%$. While these poor live on somewhere around $\$ 100$ or $\$ 200$ per person per year, the annual per capita social product is about $\$ 6,300$ for the world at large and $\$ 32,000$ for the high-income countries. 8

It is a wonderful thing about the products of thought that they are, as economists say, nonrivalrous: The intellectual labors of composing a novel are exactly the same, regardless of whether it has millions of readers or none at all. Likewise for the labors of producing music, composing software, developing a new breed of plant or animal, and discovering a new medically effective type of molecule. Millions can benefit from such intellectual efforts without adding at all to their cost. To be sure, to benefit many, the intellectual achievement must typically be physically encoded in multiple copies: in books, CDs, seeds, DNA molecule tokens, pills, or vaccines. Such physical instantiations of intellectual achievements do have a cost that rises-typically at a decreasing rateas additional copies are made. But such physical reproduction begins only after the creative intellectual labors are complete. Physical reproduction adds nothing to these intellectual labors, and these intellectual labors add nothing to the marginal cost of physical reproduction. The creative intellectual ingredient to physical reproduction is entirely cost free. Yet, the driving idea of the grand IPR initiative of recent years is that any benefit derived from any such intellectual achievement, by any person, anywhere, must be paid for, and that any unpaid-for benefit constitutes theft, piracy, counterfeiting, or worse. Even though the additional ride is entirely cost free, none are to have a free ride-no matter how desperately poor they may be and no matter how desperately they may need it. ${ }^{9}$

Before 2005, Indian law allowed only patents on processes, none on products. As a result, India had a thriving 
generic pharmaceuticals industry that cheaply supplied copies of patented medicines for poor patients throughout the world's poor regions.

But when India signed the World Trade Organization's agreement on intellectual property in 1994, it was required to institute patents on products by Jan. 1, 2005. These rules have little to do with free trade and more to do with the lobbying power of the American and European pharmaceutical industries. India's government has issued rules that will effectively end the copycat industry for newer drugs. For the world's poor, this will be a double hit-cutting off the supply of affordable medicines and removing the generic competition that drives down the cost of brand-name drugs. ${ }^{10}$

What could possibly justify blocking the supply of life-saving medicines from Indian manufacturers to the world's poorest populations? In response, one might invoke a natural right of any inventor to control the use of his invention. But this response faces three grave difficulties. First, it is hard to see why pharmaceutical firms should qualify for such exclusive inventors' rights when so much of the basic research used in their medicines is conducted at universities and public institutions with funds supplied by governments and tax-advantaged foundations. ${ }^{11}$ Second, it is very hard to explain why such a natural right of inventors should have precisely the contours enshrined in the TRIPs and TRIPs-plus agreements: Why should this natural right cover all and only the intellectual achievements that can be protected by patents (or copyrights or trademarks)? Why should this natural right expire after exactly the specified number of years? And, most perplexing, why should this natural right prohibit unauthorized use of the idea by someone who invents it independently? Third, it must also be shown that this natural right of inventors is so weighty that even the right to life of poor patients must be curtailed to accommodate it, rather than the other way around.

The difficulties of defending IPRs as natural rights are so overwhelming that most defenders of the ongoing IPR initiative appeal instead to the social utility of protecting property rights in intellectual achievements: Such rights incentivize intellectual innovation, or so we are told. The experience of recent years suggests that IPRs in seeds and medicines inspire a great deal of copycat efforts and innovative gamesmanship - attempts to influence the formulation of the rules and attempts abusively to take advantage of the rules. ${ }^{12}$ Still, it must be admitted that IPRs also encourage research efforts that result in genuinely new seeds and pharmaceuticals. So the argument from social utility cannot be dismissed.

To assess this argument, we need to ask: How does the global IPR regime now taking shape affect social utility by raising or reducing the well-being of diverse human populations? In examining this question, it is crucial to avoid the false dichotomy that asks us either to accept the emerging global IPR regime or else to renounce all hope for innovation. A third possibility was exemplified in the recent past, when IPRs were legally recognized in most affluent countries but not (or not to anything like the same extent) in most of the poorer ones. The existence of this third possibility has two implications. First, the social-utility argument for the emerging global IPR regime cannot succeed by showing merely that this regime is preferable to the complete absence of IPRs anywhere. Second, the social-utility argument for the ongoing IPR initiative fails if the decline in social utility it brings for poor populations (by reducing their access to patented seeds and 
pharmaceuticals) is greater than the increase in social utility it brings to rich populations (by enhancing corporate income from patents and by expanding the flow of new seeds and pharmaceuticals). On any plausible conception of social utility, which gives equal weight to the well-being of rich and poor human beings alike, the new global IPR regime is greatly inferior to its more differentiated predecessor.

But if the new regime is so much worse for the global poor, then why did they agree to it? Membership in the WTO is voluntary, after all, and the poor countries chose to sign up. And surely they are more reliable and more legitimate judges of their own interests than we outsiders are.

To understand why this objection fails, one must bear three points in mind. First, in the negotiations that preceded the WTO Agreement and its subsequent modifications, the representatives of the poor countries were "hobbled by a lack of know-how. Many had little understanding of what they signed up to in the Uruguay Round." 13 Even back then, poor-country representatives were facing some 28,000 pages of treaty text drafted in exclusive ("Green Room") consultations among the most powerful countries and trading blocks.

Second, most poor countries lacked the bargaining power needed to resist the imposition. All the Western freetrade rhetoric notwithstanding, the poor countries are required to pay for access to the huge markets of the rich. Any poor country is required to open its own markets widely to the corporations and banks of the rich countries and required also to commit itself to the costly enforcement of their IPRs. The World Intellectual Property Organization (WIPO), a specialized agency of the United Nations, has the task of "helping" poor countries enforce IPRs. The cost of such enforcement efforts cut into government expenditures on basic social services: "Implementing commitments to improve trade procedures and establish technical and intellectual-property standards can cost more than a year's development budget for the poorest countries." ${ }^{14}$ And the extraction of monopoly rents for foreign corporations also raises prices in the poor countries, including prices charged for seeds and essential medicines. Poor countries deemed insufficiently aggressive in the enforcement of foreign IPRs are singled out in the "301 reports" of the U.S. Trade Representative, where currently some 50 countries are held up for reprimand and exposed to actual or possible trade sanctions (www.ustr.gov). ${ }^{15}$ Poor countries deemed sufficiently aggressive in enforcing the extraction of monopoly rents for foreign corporations avoid trade sanctions. But even they get nothing like full access to the markets of the rich countries, which continue to be heavily protected through quotas, tariffs, antidumping duties, export credits, and huge subsidies to domestic producers. Such protectionist measures are most severe in precisely the areas-textiles, footwear, agricultural products-where poor countries would otherwise be most competitive. Regularly lamented by top officials of the global trading system (globalenvision. org/library/6/309), such rich-country protectionism costs the poor countries some $\$ 1000$ billion annually in lost export revenues. ${ }^{16}$

The third point we need to bear in mind is that the poor countries are heavily stratified. Even if an international treaty is disastrous for a country's poor, signing this treaty as proposed by the rich states may nonetheless be advantageous for this country's political and economic elite. It may be advantageous to them by affording them export opportunities, by winning them diplomatic recogni- 
tion and political support, by enabling them to buy arms, by protecting their ability discreetly to transfer and maintain wealth abroad, and in many other ways. Consent by the ruling elite is not then a valid indicator of advantage to the general population. This point is made vivid when we look through the list of rulers who actually signed up their countries to the WTO Agreement. Among them we find Nigeria's military dictator Sani Abacha, Myanmar's SLORC junta (State Law and Order Restoration Council), Indonesia's kleptocrat Suharto, Zimbabwe's Robert Mugabe, Zaire's Mobutu Sese Seko, and a host of less well-known tyrants of similar brutality and corruption. Even if the consent of these rulers was rational in reference to their own interests, it hardly follows that this consent was in the best interest of their oppressed subjects.

These reflections on the third point also speak to another popular defense of the new rules of the world economy. This defense points out that it is not unfair to hold people to rules that are disadvantageous to them if these people themselves have agreed to the rules beforehand. Volenti non fit iniuria-no injustice is being done to the willing. The problem with this defense is that it justifies the status quo only insofar as the consent of national populations can be inferred from the signatures of their rulers. But in countries like those just listed, we cannot plausibly consider the population to have consented through its rulers. How can a tyrant's success in subjecting a population to his rule by force of arms give him the right to consent on behalf of those he is oppressing? Does this success entitle us to count the ruler's signature as the population's consent? On any credible account of consent, the answer is no. We cannot invalidate the complaint of those now excluded from essential medicines by appealing to the prior consent of their ruler when this ruler himself lacks any moral standing to consent on their behalf. And even in cases where this ruler has some moral standing, it is still doubtful whether his consent can waive supposedly inalienable human rights of his subjects whom the rich countries' IPR initiative is depriving of secure access to essential medicinesincluding the human rights of children under five, who constitute the majority of those killed by such deprivation.

But is it not an accepted principle that those exercising effective power in a country are entitled to act on behalf of its people? Yes, indeed, it is current international practice to recognize any person or group holding effective power in a country-regardless of how they acquired or exercise it - as entitled to sell the country's resources and to dispose of the proceeds of such sales, to borrow in the country's name and thereby to impose debt service obligations upon it, to sign treaties on the country's behalf and thus to bind its present and future population, and to use state revenues to buy the means of internal repression. This practice of recognition is of great importance to us-mainly because we can gain legal title to the natural resources we need from anyone who happens to possess effective power. This practice is also well-liked among rulers, elites, and generals in the poor countries.

Yet the effects of this accepted international practice on the world's poor are devastating: The practice enables even the most hated, brutal, oppressive, corrupt, undemocratic, and unconstitutional juntas or dictators to entrench themselves. Such rulers can violently repress the people's efforts toward good governance with weapons they buy from abroad and pay for by selling the people's resources to foreigners and by mortgaging the people's future to foreign banks and 
governments. Greatly enhancing the rewards of de facto power, the practice also encourages coup attempts and civil wars, both of which often provoke opportunistic military interventions from neighboring countries. And in many (especially resource-rich) countries, these privileges make it all but impossible, even for democratically elected and well-intentioned leaders, to rein in the embezzlement of state revenues: Any attempt to hold military officers to the law is fraught with danger, because these officers know well that a coup can restore and enhance their access to state funds, which, after such a coup, would still be replenished through resource sales and still be exchangeable for the means of domestic repression. Far from being a defence against the charge that the newly globalized IPR regime is harming the global poor, the present practice of international recognition is a further example of such harming.

We have seen that, on any plausible conception of social utility, the rich countries' IPR initiative goes in the wrong direction, foreseeably causing many additional premature deaths among the global poor by cutting them off from life-saving patented medicines. Although generic producers in poor countries could manufacture such medicines very cheaply for use throughout the world's poor regions, they are no longer permitted to do so, and these medicines are now available only at the monopolist price, typically vastly higher than the marginal cost of production. ${ }^{17}$

Imagine for a moment that we really cared about social utility understood in a way that gives equal weight to the well-being of rich and poor alike. If so, we would certainly want the intellectual achievements embedded in life-saving seeds and medicines to be freely available in poor countries. But such free availability, which was standard before TRIPs, leaves two big problems unaddressed. One problem is that the health systems of many poor countries are so undeveloped that they fail to afford poor people effective access even to essential medicines that are available very cheaply or (by donation) cost free. The other problem arises from the fact that poor populations face many serious health problems that are very rare among the affluent. These special health problems are due to a variety of poverty-related factors: The global poor often lack access to minimally adequate nutrition, to clean water, to sanitation, to minimally adequate clothing and shelter, to adequate sleep and rest, and to minimal health-related knowledge and advice. And little is spent on controlling environmental hazards (such as malaria-carrying mosquitoes, parasites, dangerous pollution, etc.) in regions inhabited by poor populations-even while such hazards have been successfully eradicated from affluent regions (e.g., South Florida) with similar climate and geography.

Although the special health problems of the global poor constitute a very substantial portion of the global disease burden, they are predictably ignored under a regime that forces pharmaceutical inventor firms to recoup their research and development costs from paying patients. Such a regime foreseeably steers pharmaceutical research toward the health problems of the affluent and away from the much greater medical needs of the global poor. Vastly more money and human ingenuity are invested toward finding remedies for hair loss, skin disorders, obesity, and erectile dysfunction than toward developing effective vaccines and treatments for diseases that are decimating the world's poor. Malaria, pneumonia, diarrhea, and tuberculosis, which together account for $21 \%$ of the global disease burden, receive $0.31 \%$ 
of all public and private funds devoted to health research. ${ }^{18}$ And diseases confined to the tropics tend to be the most neglected: Of the 1393 new medicines approved between 1975 and 1999, only 13 were specifically indicated for tropical diseases and, of these 13,5 were by-products of veterinary research and 2 had been commissioned by the military. ${ }^{19}$

The problem of neglected diseases might be overcome through a different kind of IPR reform. The final article of the "Montréal Statement" suggests, as examples, "international commitments to funding health research as a global public good, and schemes that reward innovation based on health outcomes." What might such a propoor IPR reform look like more concretely? One proposal I have elaborated elsewhere envisions the creation of a second kind of pharmaceutical patent that entitles an inventor not to monopoly pricing powers, but rather to rewards proportioned to the invention's actual health impact over time. ${ }^{20}$ Such rewards, funded by a consortium of willing governments, would incentivize pharmaceutical companies to develop, first and foremost, the most cost-effective remedies for the world's neglected diseases.

In addition, this reform would reorient the incentives of such firms in highly desirable ways: Any inventor firm would have incentives to sell its innovative medicines cheaply, often even below their marginal cost of production, to help even very poor people who need them. Such a firm would have incentives to prioritize prevention over treatment (conventional patents have the opposite effect, with new treatments offering much greater profit opportunities than new vaccines). It would have incentives also to ensure that patients are fully instructed in the proper use of its medicines (dosage, compliance, etc.), so that, through wide and effective deployment, they have as great an impact on the global disease burden as possible. ${ }^{21}$ Rather than ignore poor countries as unlucrative markets, inventor firms would, moreover, have incentives to work together toward improving the heath systems of these countries to enhance the impact of their inventions there. Any inventor firm would have reason to encourage and support efforts by cheap generic producers to copy its medicines, as such copying would further increase the number of users and hence the invention's favorable impact on the global disease burden. In all these ways, the reform would align and harmonize the interests of inventor firms with those of patients and the generic drug producers-interests that currently are diametrically opposed. ${ }^{22}$ The reform would also align the moral and prudential interests of the inventor firms who, under the present regime, are forced to choose between recouping their investments in the search for essential medicines and preventing avoidable suffering and deaths.

Such a reform would be acceptable to pharmaceutical companies, especially if they retain the freedom, for each invention, to choose between the two kinds of patent. This way, these firms gain new opportunities to profit from attacking health problems prevalent among the global poor without losing any of their existing profit opportunities from traditional monopoly patents. Such a reform should also be acceptable to the taxpayers of cooperating countries, who would benefit from cheaper medicines, from additional medical knowledge, and from better protection against invasive diseases such as SARS and the avian flu. More importantly, such taxpayers would understand that any cost they bear from this reform would be correlated with a huge reduction in the global disease burden. By supporting 
the reform, a typical tax-paying household in one of the cooperating rich countries would agree to pay about $\$ 50$ of the $\$ 10$ billion that the rich countries together would need to contribute to the alternative-patent reward fund for each million premature deaths avoided. ${ }^{23}$ Taxpayers would so agree on the understanding that the alternative patent scheme would cost money if, and only if, new medicines registered under it would actually produce measurable health improvements. Would any taxpayers object to having less than one-tenth of one percent of their household income spent on avoiding a million deaths?

Of course, the details of such a propoor IPR reform need to be specified in much greater detail. It is clear nonetheless that the presently emerging global IPR regime foreseeably aggravates the catastrophic health problems of the global poor and therefore constitutes a massive violation of the human right to essential medicines. To end this violation, we need to build the political will to design and implement an appropriate IPR reform that maintains and augments the incentives to pharmaceutical innovation while removing the barriers that now effectively exclude the global poor from the benefits of pharmaceutical research. By studying the issues, signing the "Statement," and lending your support, you can join our work toward realizing the human right to essential medicines worldwide.

\section{Montréal Statement on the Human Right to Essential Medicines}

\section{Saving Lives}

1. Two billion people lack access to essential medicines. This deprivation causes immense suffering: pain, fear, loss of dignity and life.
Forty thousand people die daily as a result, the vast majority of them children under five years old.

2. Poor people lack access to essential medicines because research and development do not address their priority health needs, because health systems are inadequate, and because existing medicines are unaffordable to them.

3. This situation is contrary to ethical and legal duties, including human-rights obligations. Existing policies, rules, and institutions foreseeably give rise to deprivations on a massive scale. Alternative designs are feasible; reforms are urgently required. We have a responsibility to achieve a social and international order in which human rights-including the right to essential medicinesare fully realized. This obligation must be recognised and reflected in the design of institutions and policies. On the national and global levels, policies, rules, and institutions must be conducive to the realization of the right to essential medicines. At a minimum, trade agreements, intellectual property laws, loans, aid, and other international arrangements as well as national institutions, laws, and policies must be designed so as to avoid violation of this right.

4. States Parties to international human-rights treaties have a core obligation to respect, protect, and fulfil the right to essential medicines. This core obligation requires immediate and effective measures and is not subject to progressive implementation. Despite many resolutions and statements of commitment in recent years, far too little has been ac- 
complished toward the effective realization of the right to health, including the right to essential medicines. In view of the enormous and persistent suffering and loss of life and health due to lack of access to essential medicines, and the risk of outbreak of new pandemics, the world's peoples and governments must dedicate themselves to the full realization of this right.

\section{Assuring Access to Existing Treatments}

5. The essential medicines covered by this right are those that satisfy the priority health care needs of the population, in light of their public health relevance, proven quality, efficacy and safety, and comparative cost-effectiveness. The Essential Drugs List provided by the World Health Organization is a model policy guide for the national determination of drugs and other health goods deemed essential for the population of each country.

6. The implementation, monitoring and evaluation of national medicines policies must be based on the principle of equitable access to basic services for all and the objective of the highest attainable standard of health. 'Highest attainable,' in this context, refers not to a theoretical upper limit of human functioning, but rather to what could be achieved through improvements in product development and health system performance, overcoming of political and economic barriers and better utilization of available resources, including international assistance and cooperation. Accordingly, the national list of essential medicines should be constantly up- dated to meet the evolving needs of the population. The process of establishing and updating national medicine policies must be participatory: it should include meaningful involvement of professional associations, patient and consumer groups, nongovernmental organizations, and representatives of rural communities and vulnerable groups. It must also provide mechanisms of transparency and accountability through clearly defined objectives, benchmarks and indicators, regular monitoring and evaluation, and procedures for redress and appeal, including judicial remedies, in case the system is too slow or fails to provide essential medicines.

7. The human right to essential medicines requires that national health systems guarantee at all times that the population receive all essential medicines in adequate amounts, of assured quality, at the appropriate time and in the appropriate dosage. Those who receive the medicines must be adequately informed and consent to the treatment. The essential drugs made available must be at a price the individual and the community can afford.

\section{Overcoming Political and}

\section{Economic Barriers}

8. Social and economic conditions determine population health. Moreover, they are vital to access to medicines. As a result, realizing the right to essential medicines requires a strategy to strengthen health systems, including sufficient and adequately trained health personnel and eliminating poverty and social disparities. 
9. The responsibility of governments for the fulfillment of human rights includes international assistance and cooperation. Affluent countries must, therefore, ensure fairer trade and investment, eliminate crippling debt, and contribute equitably to international assistance aimed at facilitating the full realization of the right to essential medicines.

10. All governments have the duty, through their voice and vote in international financial, monetary and trade institutions and development agencies, and in their bilateral development policies and programmes, to ensure that the human right to essential medicines is furthered in the lending, trade and aid policies of those institutions and agencies.

11. States are entitled and obliged to take all reasonable and feasible steps to enable access to essential medicines, including adopting trade practices and using trade flexibilities and safeguards, such as compulsory licensing and parallel importing. All States must abstain from measures-including political interference and trade pressuresthat hamper the implementation of such flexibilities and safeguards, or otherwise impede access to medicines.

12. The responsibilities for the elimination of poverty are shared by the less affluent countries. Poverty reduction strategies must be participatory, transparent, and focused on the most vulnerable segments of the population. Measures and policies to reduce poverty must be compatible with States' human rights obligations, including the human right to essential medicines.
13. International institutions and their member states have a duty to respect and actively promote health as a human right. Accordingly, they must ensure that international agreements relating to the protection of intellectual property do not result in violation of the human right to essential medicines. On the national and global levels, all policy decisions or agreements likely to have a significant effect on health should be preceded by a transparent and independent health impact assessment. All parties to the decision or agreement are obligated to minimise foreseeable negative impacts on health identified by such assessment.

\section{Health Innovation as a Global Public Good}

14. The price of patented medicines is a major barrier to the realization of the human right to share in scientific advancement and its benefits, including innovations in essential medicines. The only justification for pharmaceutical patents is the stimulation of innovation. However, the present incentive system results in high consumer prices and in millions of people being denied the right to affordable medicines. This system also leads to a skewing of research priorities, driven by return on investment rather than priority health needs and outcomes.

15. Governments must, therefore, adopt and implement alternative innovation systems that ensure that research and development are sufficient to meet priority health needs. Among these alternatives are inter- 
national commitments to funding health research as a global public good, and schemes that reward innovation based on health outcomes. Such alternative innovation systems must be designed to prioritize the right to essential medicines.

To sign the "Montréal Statement on the Human Right to Essential Medicines," go to www.accessmeds.org.

\section{Notes}

1. As used in the statement and in the comment, the term medicines covers pharmaceuticals used for medical treatment or prevention (vaccines), and essential medicines are understood as those that can have significant effects on patients' basic functionings or survival prospects.

2. During the life of its primary patent, the patent holder can take out additional patents on a wide range of often trivial or irrelevant aspects of a successful drug, such as its packaging or dosing regimen. Having been applied for later, these additional patents outlast the primary patent. They ensure that, even after the primary patent expires, the patent holder retains the right to be notified by any firm planning to commence generic production of the drug. Once notified, the patent holder can then threaten or initiate legal action that, though it has no chance of ultimate success, can delay commencement of generic production by several years or even deter generic production altogether. See NIHCM Foundation. Changing pattern of pharmaceutical innovation; 2002. Available at: www.nihcm.org.

3. Among the pharmaceutical research tools for which patents have been granted are expressed sequence tags (ESTs), restriction enzymes, screening systems, techniques related to DNA sequencing, and single nucleotide polymorphisms (SNPs). For details, see Rai AK, Eisenberg RS. Bayh-Dole reform and the progress of biomedicine. Law $\mathcal{E}$ Contemporary Problems 2003;66(1):289314 (also available at: www.law.duke.edu/ journals /66LCPRai).

4. United Nations Development Program. Human Development Report 2005. New York: United Nations Development Program;
2005:24,44 (also available at: hdr.undp.org/ reports/global/2005).

5. United Nations Development Program. Human Development Report 1998. New York: Oxford University Press; 1998:49.

6. World Health Organization. The World Health Report 2004. Geneva: WHO Publications; 2004:120-5 (also available at: www.who.int/ whr /2004).

7. United Nations Children's Fund. The State of the World's Children 2005. New York: United Nations Children's Fund; 2005:inside front cover (also available at: www.unicef.org/ sowc05/english UNICEF 2005).

8. World Bank. World Development Report 2006. New York: Oxford University Press; 2005: 292-3.

9. It may be inappropriate to use the expression "free riders" for very poor people who enjoy, at no cost to anyone, some public benefit. Kevin Outterson has proposed to speak here of "fair followers" instead. See Outterson K. Fair followers: Expanding access to generic pharmaceuticals for low- and middle-income populations. In: Cohen JC, Illingworth P, Schuklenk U, eds. The Power of Pills: Social, Ethical, and Legal Issues in Drug Development, Marketing, and Pricing. London: Pluto Press; 2006.

10. Editorial. India's choice. The New York Times 2005 Jan 18.

11. This pattern emerged in the United States after Congress, in 1980, passed the BayhDole Act, which allows pharmaceutical companies, professors, and clinicians to cash in on patented applications of basic research done at universities or at the National Institutes of Health. For a brief account with further references, see note 3, Rai, Eisenberg 2003. See also Angell M. The truth about the drug companies. The New York Review of Books 2004,51(12):52-8 (also available at: www.nybooks.com/articles/17244) and Light D. Basic research funds to discover new drugs: who contributes how much? In: Burke MA, de Francisco A, eds. Monitoring Financial Flows for Health Research 2005: Behind the Global Numbers. Geneva: Global Forum for Health Research; 2006:29-46.

12. Goozner M. The $\$ 800$ Million Pill: The Truth Behind the Cost of New Drugs. Berkeley and Los Angeles: University of California Press; 2004, ch. 8; Angell M. The Truth about the Drug Companies: How They Deceive Us and What to Do about It. New York: Random House; 2004, ch. 10.

13. White man's shame. The Economist 1999;Sept 25:89.

14. See note 13, White man's shame 1999. 
15. This kind of relentless pressure goes a long way toward explaining why no poor country has ever tried to issue a compulsory licence for a patented medicine, despite the fact that such compulsory licences are theoretically permissible pursuant to paragraph 6 of the 2001 Doha Declaration.

16. This compares to about $\$ 80$ billion the poor countries receive annually (2004) in official development assistance. See www.oecd.org/ document/9/0,2340,en_2649_33721_1893129_ 1_1_1_1,00.html.

17. AIDS drugs and second-line tuberculosis medicines are prominent examples.

18. Global Forum for Health Research. The 10/90 Report on Health Research 2003-2004. Geneva: Global Forum for Health Research; 2004:122 (also available at: www.globalforumhealth.org).

19. Trouiller P, Torreele E, Olliaro P, White N, Foster S, Wirth D, Pécoul B. Drugs for neglected diseases: A failure of the market and a public health failure? Tropical Medicine and International Health 2001;6(11):945-51; Drugs for Neglected Diseases Working Group. Fatal Imbalance: The Crisis in Research and Development for Drugs for Neglected Diseases. Geneva: MSF and Drugs for Neglected Diseases Working Group; 2001:11 (also available at: www.msf.org/source/access / 2001/fatal/ fatal.pdf).

20. Pogge T. Human rights and global health: A research program. In: Barry C, Pogge T, eds.
Global Institutions and Responsibilities. Oxford: Blackwell Publishers; 2005:190-217.

21. The absence of such incentives under the present rules gravely undermines the effectiveness even of donated drugs delivered into poor regions. See United Nations Development Program. Human Development Report 2001. New York: Oxford University Press; 2001:101 (also available at: www.undp.org/ hdr2001).

22. This opposition was dramatically displayed when a coalition of 31 pharmaceutical companies went to court in South Africa to prevent their inventions from being reproduced by local generic producers and sold cheaply to desperate patients whose life depended on affordable access to these retroviral drugs. In April 2001, their attempted law suit collapsed under a barrage of worldwide public criticism. See Barnard D. In the High Court of South Africa, Case No. 4138/ 98: The global politics of access to low-cost AIDS drugs in poor countries. Kennedy Institute of Ethics Journal 2002;12(2):159-74.

23. I am assuming here that the contribution of the rich countries would be spread over some 200 million tax-paying households, which is roughly the number of households in the European Union. The contribution of typical tax-paying households in the rich countries would be much lower (under \$25 per million premature deaths avoided), if all rich countries agreed to cooperate. 